(c) Elsevier/INRA

Original article

\title{
Starvation and desiccation tolerance in Drosophila melanogaster: differences between European, North African and Afrotropical populations
}

\author{
JL Da Lage, P Capy, JR David * \\ CNRS, Laboratoire de Biologie et Génétique Evolutives, \\ 91198 Gif-sur-Yvette Cedex, France
}

(Received 5 January 1990; accepted 13 July 1990)

\begin{abstract}
Summary - Starvation tolerance (mean survival time with water only) and desiccation tolerance (mean survival with no food and zero \% humidity) were measured at $17^{\circ} \mathrm{C}$ in adult flies from 3 different geographic populations living in different climates. A fairly large uncontrolled variability was observed and two successive generations of the various isofemale lines were investigated for each population. For desiccation tolerance, a Tunisian population from an oasis was found to be more tolerant than French or Congolian populations. For starvation tolerance, the survival of the Congolian population was about twice the values found for French or Tunisian flies. It is suggested that the Afrotropical flies which live in a hot, humid environment, are poorly protected against desiccation but need a high starvation tolerance because of their high metabolic rate due to the high ambient temperature.
\end{abstract}

Drosophila melanogaster / geographic race / ecological genetics / environmental stress

Résumé - Tolérance à l'inanition et à la dessiccation chez Drosophila melanogaster : différences entre populations d'Europe, d'Afrique du Nord et d'Afrique tropicale. $\mathrm{La}$ tolérance d̀ l'inanition (durée de survie en présence seulement d'eau) et la tolérance d̀ la dessiccation (durée de survie sans nourriture en atmosphère sèche) ont été étudiées à $1 \gamma^{\circ} \mathrm{C}$ sur des mouches adultes provenant de 9 régions géographiques. Une assez forte variabilité non contrôlée a été observée et 2 générations successives ont été étudiées pour les diverses lignées isofemelles de chaque population. Pour la tolérance à la dessiccation, la population tunisienne provenant d'une oasis a été trouvée plus tolérante que les populations de France ou du Congo. Pour la résistance à l'inanition, la population du Congo est environ 2 fois plus tolérante que les populations de France ou de Tunisie. Il est proposé que les populations d'Afrique tropicale, qui vivent dans un environnement chaud et humide, sont peu protégées contre la dessiccation mais qu'elles ont besoin d'une forte résistance à l'inanition, compte tenu du fait que la chaleur ambiante leur impose un métabolisme élevé.

Drosophile / race géographique / génétique écologique / stress dû à l'environnement

* Correspondence and reprints 


\section{INTRODUCTION}

During the last decade, attention has been drawn to the possible significance of abiotic environmental stress for the evolutionary biology of Drosophila species (David et al, 1983; Parsons, 1983, 1987). Climatic environmental stress differs considerably according to geographic parameters and significant variations between populations are more likely to be found in species with a broad geographic range. In this respect, $D$ melanogaster, which proliferates both in temperate and tropical countries (David and Tsacas, 1981; David and Capy, 1988) has become an excellent model for checking local adaptations.

Drosophila adults are poorly protected against desiccation (David et al, 1983) and the water balance is maintained by water ingestion (Fairbanks and Burch, 1970; Arlian and Eckstrand, 1975). In addition the availability of resources is variable among localities and seasons, and the demography principally depends on two parameters, ie resources and favorable temperature (David et al, 1983; David et al, 1984).

Variations in desiccation tolerance have been mainly investigated in Australian natural populations (Parsons, 1980; Stanley and Parsons, 1981; Davidson, 1988, 1989). Temperate populations were found to be more resistant to desiccation stress than populations from subtropical regions, in agreement with what could be expected from consideration of local climates. Recent investigations (Hoffman and Parsons, 1989a,b) have suggested that tolerance to different stress could be mediated by the same basic physiological process, namely a lower resting metabolic rate. According to this hypothesis, we may expect that starvation tolerance, which depends on the amount of available reserves, and especially of lipids (David et al, 1975) could also be related to a lower metabolic rate and to other environmental stress (Hoffmann and Parsons, 1989a). However, starvation tolerance has been mainly investigated for its physiological significance (David et al, 1975; Da Lage et al, 1989) and for comparing artifically selected lines (Service et al, 1985; Service, 1987; Hoffmann and Parsons, 1989b) while natural populations are poorly documented.

In a previous paper (David and Capy, 1988), we suggested that, with respect to their history, natural populations of $D$ melanogaster could be divided into three groups : 1) ancestral populations found in the Afrotropical region south of the Sahara; 2) "old" or "ancient" populations, established independently of the activity of modern man, and found in the Eurasian continent; 3 ) "new" or "recent" populations, introduced by man a few centuries ago and found in America and Australia. Desiccation tolerance studies have focused on such recent populations, while almost nothing is known of more ancient populations.

In the present study, we have compared three types of populations from different latitudes and living under very different climatic conditions. Using the isofemale line technique, we have simultaneously studied for each line the desiccation and starvation tolerance by measuring adult survival in dry and humid conditions. 


\section{MATERIALS AND METHODS}

Three natural populations were compared. An equatorial African population from Loua near Brazzaville (Congo) living all year round in a humid, warm and favorable environment. A North African population from a Tunisian oasis (Nasrallah near Kairouan) exposed each year to strong heat-desiccation stress during the Summer months, as is typical of all Mediterranean climates. A population from southern France, represented by two samples, Moulis and Lorp, two localities a few kilometers apart from St-Girons near Toulouse. This population lived under a cool temperate climate without any strong desiccation stress but faced the difficult problem of overwintering during the coldest months of the year.

Samples were collected using either banana fermenting baits or by sweeping over natural breeding sites, ie Opuntia fruits in Tunisia or manihot peelings in Congo. In each case, wild collected females were used to initiate isofemale lines. These lines were kept in the laboratory for a number of generations ranging between 5 and 12 before the experiments were undertaken. Population size in each line was always more than 20 flies for each generation.

Starvation and desiccation tolerance was studied by measuring the survival duration of adult flies kept without food. With the isofemale line technique, male and female data are correlated (David, 1979) since both sexes of each line exhibit a genetic similarity and, moreover, are submitted to a common environment; therefore only males were compared for the 3 geographic populations. The experimental procedures have been described in a previous paper (Da Lage et al, 1989) and are summarized here. For each line, the larvae were grown on a killed yeast, high nutrient medium (David and Clavel, 1965). On emergence, adults were etherized and distributed into groups of 10 flies. Each group of 10 was fed on killed yeast medium for 2 or 3 days and then transferred to the experimental vials. For starvation tolerance, water was provided in each vial. For desiccation tolerance, a relative humidity of $0 \%$ was maintained with silica gel. Experiments were made at $17^{\circ} \mathrm{C}$ since, at this temperature, the survival time is longer so that the mean value is calculated with better precision. For each isofemale line and treatment, two independent vials, ie 20 males, were studied. The repeatability of the measurements was assessed, by studying two successive generations for each population. Early in the trials it was apparent that repeatability was not excellent, as is often the case with physiological traits (Carton et al, 1989; Da Lage et al, 1989), so that considering the results at the individual level would be almost meaningless. In most of the following analyses, the mean of each line is considered as the basic observation, and the variability between lines will mainly be used for calculating the standard error of the mean of each population.

\section{RESULTS}

\section{Survival time in dry and humid conditions}

The mean survival durations of the various populations are given in Table I. As expected (Da Lage et al, 1989), life duration is always much less under desiccating conditions, showing the specific effects of the desiccation stress. With one exception 
(starvation tolerance of the Tunisian population), the differences between the two successive generations were not significant. In the case of the Tunisian population, a third generation was studied and the following average values (in hours) were obtained : $m=31.22 \pm 1.01(n=30)$ for desiccation tolerance, and $m=75.41 \pm 2.91$ $(n=25)$ for starvation tolerance. Compared to table I values, we find that desiccation tolerance is significantly lower than in the first two generations, while for starvation tolerance, the mean is intermediate and not significantly different from the other two. These fluctuations illustrate the possible low repeatability of some results, due to uncontrolled variations in the experimental conditions. For the Tunisian population, the mean life duration in dry conditions of the 3 generations is $36.8 \mathrm{~h}$; the true value could be a little higher $(38-39 \mathrm{~h})$ if we admit that the third generation was submitted to some uncontrolled, unfavorable effects. For starvation tolerance, on the other hand, the mean value of the 3 generations, ie $76 \mathrm{~h}$, may be considered as the best estimate for that population.

Table I. Duration of life (h), in absence of food, of flies from various populations submitted to desiccating conditions (desiccation tolerance) or provided with water (starvation tolerance).

\begin{tabular}{|c|c|c|c|c|c|c|c|c|c|c|c|}
\hline \multirow[t]{2}{*}{ Population } & \multirow[t]{2}{*}{ Gener } & \multicolumn{5}{|c|}{ Desiccated-air } & \multicolumn{5}{|c|}{ Water } \\
\hline & & $n$ & $m$ & $c v$ & $t$ & $r$ & $n$ & $m$ & $c v$ & $t$ & $r$ \\
\hline $\begin{array}{l}\text { Congo } \\
\text { (Loua) }\end{array}$ & $\begin{array}{l}\text { G1 } \\
\text { G2 } \\
\text { M }\end{array}$ & $\begin{array}{l}12 \\
11 \\
11\end{array}$ & $\begin{array}{l}26.21 \pm 1.58 \\
22.96 \pm 0.95 \\
24.82 \pm 0.81\end{array}$ & $\begin{array}{l}20.9 \\
13.8 \\
10.9\end{array}$ & $\begin{array}{l}0.35 \\
0.16\end{array}$ & -0.32 & $\begin{array}{l}9 \\
9 \\
8\end{array}$ & $\begin{array}{l}124.23 \pm 5.08 \\
140.73 \pm 4.81 \\
132.38 \pm 4.63\end{array}$ & $\begin{array}{r}12.3 \\
10.3 \\
9.9\end{array}$ & $\begin{array}{l}0.28 \\
0.17\end{array}$ & 0.44 \\
\hline $\begin{array}{l}\text { Tunisia } \\
\text { (Nasrallah) }\end{array}$ & $\begin{array}{l}\mathrm{G} 1 \\
\mathrm{G} 2 \\
\mathrm{M}\end{array}$ & $\begin{array}{l}31 \\
31 \\
31\end{array}$ & $\begin{array}{l}40.03 \pm 0.81 \\
39.09 \pm 0.93 \\
39.45 \pm 0.63\end{array}$ & $\begin{array}{r}11.3 \\
13.2 \\
8.9\end{array}$ & $\begin{array}{l}0.20 \\
0.31\end{array}$ & 0.18 & $\begin{array}{l}32 \\
31 \\
31\end{array}$ & $\begin{array}{l}69.00 \pm 2.05 \\
84.35 \pm 2.54 \\
76.75 \pm 2.20\end{array}$ & $\begin{array}{l}16.8 \\
16.7 \\
16.0\end{array}$ & $\begin{array}{l}0.19 \\
0.27\end{array}$ & $0.77^{*}$ \\
\hline $\begin{array}{l}\text { France } \\
\text { (Lorp) }\end{array}$ & $\begin{array}{l}\text { G1 } \\
\text { G2 } \\
\text { M }\end{array}$ & $\begin{array}{l}13 \\
11 \\
11\end{array}$ & $\begin{array}{l}29.75 \pm 0.96 \\
30.41 \pm 0.93 \\
29.87 \pm 1.02\end{array}$ & $\begin{array}{l}11.6 \\
10.2 \\
11.4\end{array}$ & $\begin{array}{l}0.15 \\
0.09\end{array}$ & 0.65 & $\begin{array}{l}13 \\
11 \\
11\end{array}$ & $\begin{array}{l}64.51 \pm 1.70 \\
67.83 \pm 4.12 \\
66.51 \pm 2.77\end{array}$ & $\begin{array}{r}9.5 \\
20.1 \\
13.8\end{array}$ & $\begin{array}{l}0.14 \\
0.53\end{array}$ & 0.64 \\
\hline $\begin{array}{l}\text { France } \\
\text { (Moulis) }\end{array}$ & $\begin{array}{l}\text { G1 } \\
\text { G2 } \\
\text { M }\end{array}$ & $\begin{array}{l}13 \\
16 \\
11\end{array}$ & $\begin{array}{l}25.43 \pm 1.19 \\
24.99 \pm 1.40 \\
25.76 \pm 1.24\end{array}$ & $\begin{array}{l}16.8 \\
22.4 \\
15.9\end{array}$ & $\begin{array}{l}0.18 \\
0.26\end{array}$ & 0.25 & $\begin{array}{l}10 \\
17 \\
10\end{array}$ & $\begin{array}{l}63.55 \pm 4.15 \\
53.46 \pm 1.71 \\
58.39 \pm 2.10\end{array}$ & $\begin{array}{l}20.7 \\
13.2 \\
11.4\end{array}$ & $\begin{array}{l}0.40 \\
0.25\end{array}$ & -0.31 \\
\hline $\begin{array}{l}\text { France } \\
\text { (Total) }\end{array}$ & $\begin{array}{l}\text { G1 } \\
\text { G2 } \\
\text { M }\end{array}$ & $\begin{array}{l}26 \\
27 \\
22\end{array}$ & $\begin{array}{l}27.59 \pm 0.86 \\
27.20 \pm 1.04 \\
27.95 \pm 0.90\end{array}$ & $\begin{array}{l}15.9 \\
19.8 \\
15.0\end{array}$ & & 0.50 & $\begin{array}{l}23 \\
28 \\
21\end{array}$ & $\begin{array}{l}64.09 \pm 1.99 \\
59.10 \pm 2.31 \\
62.64 \pm 1.95\end{array}$ & $\begin{array}{l}14.9 \\
20.7 \\
14.2\end{array}$ & & 0.20 \\
\hline
\end{tabular}

gener: generation; G1: first generation; G2: second generation; M: mean of the lines studied in the two successive generations; $n$ : number of lines; $m$ : mean survival of $\mathbf{h} \pm$ standard error; CV: coefficient of variation between the lines; $t$ : coefficient of intraclass correlation; $r$ : correlation between G1 and G2. Significance: ${ }^{*} P<0.05$. 
For each generation and population, a one-way ANOVA (data not shown) indicated that the between line variance was always significantly higher than the within line variance. Such a result is often considered to be an indication of the occurrence of genetic variations between lines (Hoffmann and Parsons, 1988; Carton et al, 1989; Capy et al, 1990). A way to appreciate the amount of variation between lines is to calculate the coefficient of intraclass correlation, $t$. The values given in table I range between 0.09 and 0.53 , with mean values of $0.21 \pm 0.03$ and $0.28 \pm 0.05(n=8)$ for dry and humid conditions respectively; these values are significantly different from zero $(P<0.01)$. Another way to demonstrate genetic variations between lines is to show that their mean values are repeatable in different generations (Carton et al, 1989; Davidson, 1989). The correlation coefficients between generations (table 1) are generally low and only one (starvation tolerance, Tunisia) is significant. The overall mean of these coefficients $(m=0.29 \pm 0.15$, $n=8$ ) is not significantly different from zero, again suggesting that variations between lines may arise from uncontrolled, common-environment effects more than from genetic differences.

\section{Comparison between geographic populations}

For the two French samples, Lorp and Moulis, the mean values are not statistically different, with one exception, starvation tolerance in generation 2. Of course, no difference was expected, since the two samples were collected a few kilometers apart, under similar ecological conditions. The overall similarity of these results allows the pooling of the observations into a unique French sample, as shown in table I.

All possible comparisons between French, Tunisian and Congolian flies were made using the Student's $t$-test, and the results are given in table II. The conclusions may be summarized in a simple way.

Table II. Comparisons of the different populations. $d$ : difference in mean survival of the two populations compared.

\begin{tabular}{|c|c|c|c|c|c|c|c|}
\hline \multirow{2}{*}{\multicolumn{2}{|c|}{$\begin{array}{l}\text { Compa- } \\
\text { rison }\end{array}$}} & \multicolumn{3}{|c|}{ Desiccated-air } & \multicolumn{3}{|c|}{ Water } \\
\hline & & $G 1$ & $G 2$ & $M$ & $G 1$ & G2 & $M$ \\
\hline $\begin{array}{l}\text { Congo } \\
\text { Tunisia }\end{array}$ & $\begin{array}{l}d \\
t\end{array}$ & $\begin{array}{c}-13.82 \pm 2.20 \\
6.28^{* *}\end{array}$ & $\begin{array}{c}-16.13 \pm 2.11 \\
7.65^{* *}\end{array}$ & $\begin{array}{c}-14.43 \pm 1.56 \\
9.37^{* *}\end{array}$ & $\begin{array}{c}55.23 \pm 6.34 \\
8.71^{* *}\end{array}$ & $\begin{array}{c}56.50 \pm 7.35 \\
7.68^{* *}\end{array}$ & $\begin{array}{c}56.23 \pm 6.62 \\
8.49^{* *}\end{array}$ \\
\hline $\begin{array}{l}\text { Congo } \\
\text { France }\end{array}$ & $\begin{array}{c}d \\
t\end{array}$ & $\begin{array}{c}-1.38 \pm 2.30 \\
0.60\end{array}$ & $\begin{array}{c}-4.24 \pm 2.41 \\
1.76\end{array}$ & $\begin{array}{c}-3.13 \pm 1.95 \\
1.61\end{array}$ & $\begin{array}{c}60.14 \pm 6.15 \\
9.78^{* *}\end{array}$ & $\begin{array}{c}81.63 \pm 6.67 \\
12.24^{* *}\end{array}$ & $\begin{array}{c}70.34 \pm 5.80 \\
12.13^{* *}\end{array}$ \\
\hline $\begin{array}{l}\text { Tunisia } \\
\text { France }\end{array}$ & $\begin{array}{l}d \\
t\end{array}$ & $\begin{array}{c}12.44 \pm 1.85 \\
6.72^{* *}\end{array}$ & $\begin{array}{c}11.89 \pm 1.86 \\
6.39^{* *}\end{array}$ & $\begin{array}{c}11.50 \pm 1.50 \\
7.67^{* *}\end{array}$ & $\begin{array}{l}4.91 \pm 4.16 \\
1.18\end{array}$ & $\begin{array}{c}25.25 \pm 4.93 \\
5.12^{* *}\end{array}$ & $\begin{array}{c}14.11 \pm 4.39 \\
3.21^{* *}\end{array}$ \\
\hline
\end{tabular}

$t$ : Student's parameter; $G 1$ : first generation; $G 2$ : second generation; $M$ : mean of two generations. Significance: ${ }^{*} P<0.05 ;{ }^{* *} P<0.01$. 
Under desiccating conditions, the populations from France and Congo are not different, with a mean survival times of about $26 \mathrm{~h}$. On the other hand, the survival time is significantly longer (38-39 h) in the Tunisian population.

In the presence of water, the ranking of the populations differs. A small difference, not always significant, may exist between Tunisia and France, with survival times of 77 and $63 \mathrm{~h}$ respectively. The Congolian population is, by contrast, very different, with an average survival time of 133 hours, $i e$ twice the value found for French flies. However, in spite of such a large average difference, some overlap exists between the Afrotropical and the Tunisian population when the distributions of the isofemale lines are considered, as shown in figure 1.

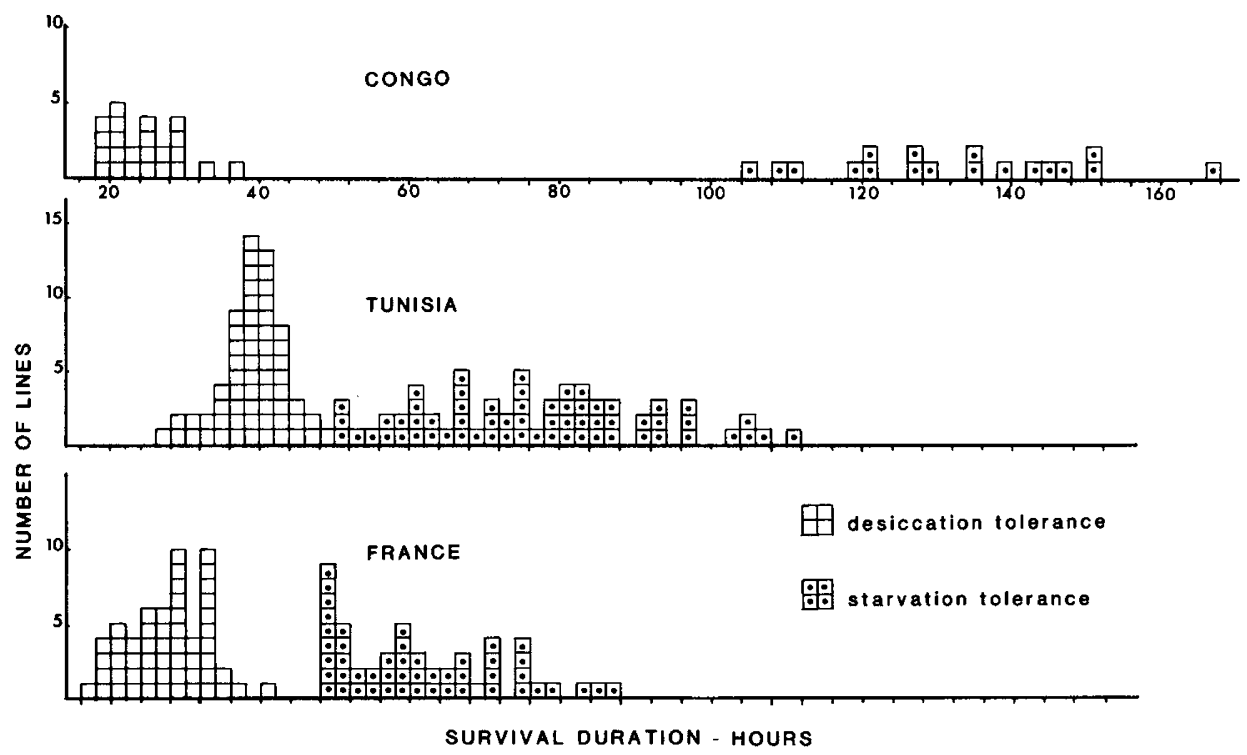

Fig 1. Distribution of the mean survival durations of the isofemale lines of the 3 geographic populations. Because of the low correlation between the two successive generations, all the values are shown.

\section{Relationship between survival in dry and humid conditions}

As discussed by Da Lage et al (1989), such a comparison may help to measure the specific effects of the desiccation stress. For each line, two traits will be considered here: the difference between survival in humid or dry conditions, and the ratio of these two values. The results are given in table III.

Differences between generations are not significant, except for the Tunisian population. In addition the correlations between generations are generally low and non significant, except for the Tunisian population. If we consider the means (difference in survival duration or ratio), we find that French and Tunisian flies are not different. The average survival difference between humid and dry conditions 
Table III. Relationships between starvation and desiccation tolerances in different populations. $n$ : number of lines; difference: survival difference between humid and dry conditions; ratio: ratio of survival times in humid and dry conditions; $G 1, G 2$ : first and second generation; comp: comparison of the two generations, using $t$ test and correlation. Significance: ${ }^{*} P<0.05 ;{ }^{* *} P<0.01$.

\begin{tabular}{|c|c|c|c|c|c|c|c|c|c|}
\hline \multirow[t]{2}{*}{ Population } & & \multirow[b]{2}{*}{$n$} & \multicolumn{3}{|c|}{ Difference } & \multicolumn{3}{|c|}{ Ratio } & \multirow{2}{*}{$\begin{array}{l}\text { Correlation } \\
\text { humid-dry }\end{array}$} \\
\hline & & & $m$ & $c v$ & $r$ & $m$ & $c v$ & $r$ & \\
\hline $\begin{array}{l}\text { Congo } \\
\quad \text { (Loua) }\end{array}$ & $\begin{array}{c}\mathrm{G} 1 \\
\mathrm{G} 2 \\
\text { comp }\end{array}$ & $\begin{array}{l}9 \\
9\end{array}$ & $\begin{array}{r}97.23 \pm 6.05 \\
117.54 \pm 4.79 \\
1.87\end{array}$ & $\begin{array}{l}18.7 \\
12.2\end{array}$ & 0.42 & $\begin{array}{c}4.81 \pm 0.42 \\
6.17 \pm 0.33 \\
1.80\end{array}$ & $\begin{array}{l}26.3 \\
15.9\end{array}$ & -0.03 & $\begin{array}{r}-0.37 \\
0.17\end{array}$ \\
\hline $\begin{array}{l}\text { Tunisia } \\
\qquad \text { (Nasrallah) } \\
\text { France } \\
\quad \text { (Total) }\end{array}$ & $\begin{array}{c}\text { G1 } \\
\text { G2 } \\
\text { comp } \\
\text { G1 } \\
\text { G2 } \\
\text { comp }\end{array}$ & $\begin{array}{l}31 \\
30 \\
\\
23 \\
26\end{array}$ & $\begin{array}{c}28.69 \pm 2.16 \\
45.61 \pm 2.82 \\
3.43^{* *} \\
36.51 \pm 1.73 \\
31.19 \pm 1.99 \\
1.41\end{array}$ & $\begin{array}{l}41.8 \\
33.8\end{array}$ & $0.74^{*}$ & $\begin{array}{c}1.73 \pm 0.06 \\
2.21 \pm 0.10 \\
3.00^{* *} \\
2.35 \pm 0.08 \\
2.17 \pm 0.08 \\
0.79\end{array}$ & $\begin{array}{l}20.6 \\
23.9 \\
\\
16.8 \\
19.0\end{array}$ & $0.63^{*}$ & $\begin{array}{r}0.14 \\
-0.03\end{array}$ \\
\hline
\end{tabular}

survival times is about $35 \mathrm{~h}$ while the average ratio is about 2.1. The Congolian population, by contrast, is completely different, with a mean ration of 5.5 and a mean difference of $107 \mathrm{~h}$. These observations are summarized in figure 2 which shows that, in spite of the large average difference between Afrotropical and temperate flies, a small overlap exists when single isofemale lines are considered. Finally the correlations between starvation and desiccation tolerance are close to zero, except in the French population.

\section{DISCUSSION AND CONCLUSION}

With the possible exception of French flies, our data confirm a previous result (Da Lage et al, 1989) concerning the physiological independence of starvation and desiccation tolerance. In the presence of water, and when the temperature is not extreme, death occurs when all reserves, especially the lipids, have been exhausted (David et al, 1975; Da Lage et al, 1989). On the other hand, under desiccating conditions, the lipids are not exhausted before death occurs (Da Lage et al, 1989) and the tolerance of the adult fly seems dependent on its capacity to control the opening of its spiracles (Fairbanks and Burch, 1970; Arlian and Eckstrand, 1975; Hoffman and Parsons, 1989b). In selection experiments for increased desiccation tolerance, Hoffmann and Parsons (1989b) found a correlated response for increased starvation tolerance. A similar positive correlation was also found by Service et al (1985) and Service (1987) in lines selected for postponed senescence. As discussed by Hoffmann and Parsons (1989a), such a correlation could be explained by a lowering of the resting metabolic activity. Obviously the situation which prevails in natural populations deserves further investigation. 

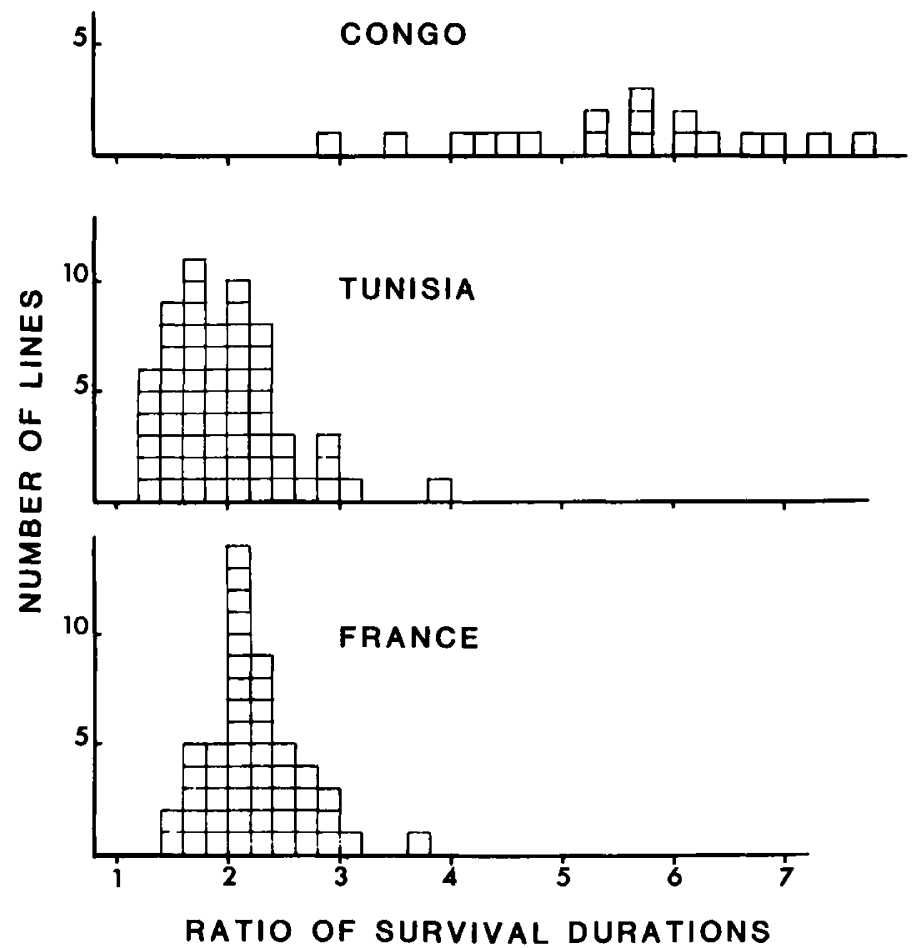

Fig 2. Distributions of the ratio of starvation tolerance over desiccation tolerance among the 3 geographic populations. Individual values of all isofemale lines are given.

A significant heterogeneity between isofemale lines is often considered to be an indication of genetic differences (Parsons, 1983). However, the heterogeneity may also occur from common environmental effects, ie from the fact that the lines are grown in different vials. In the present study, the low correlation observed between the two successive generations is an argument for such common-environment effects.

A convenient estimate of the variability between lines is the coefficient of intraclass correlation. If common-environment effects can be neglected, as is the case for many morphological traits (Capy et al, 1990), the intraclass correlation is related to genetic variations (Falconer, 1981; Slatkin, 1981; Hoffmann and Parsons, 1988). If dominance and epistatic effects are neglected, we expect to find $t=0.5 h^{2}$. However, there is not a priori reason for neglecting dominance or epistatic effects and a general expectation is that the ratio $h^{2} / t$ will range between 1 and 2 . In the present study, we found a fairly low average value for $t$ of $0.25 \pm 0.03$, which is accounted for, in part, by non genetic effects. Therefore the "true isofemale line heritability" should be lower, suggesting also a low narrow sense heritability $h^{2}$. However, in their selection for starvation tolerance, Hoffmann and Parsons (1989b) found a high value (0.64) for the realized heritability. Again, more extensive studies on these fitness traits are needed. 
The variations between geographic populations need to be discussed from various points of view. With only a few exceptions, the mean values obtained for the two generations of a given population are similar and not statistically different. On the other hand, the averages of a single line may be quite different in the two generations, due to uncontrolled fluctuations in the experimental conditions, and especially in larval density. The fact that the overal mean remained stable suggests that the uncontrolled fluctuations were the same in each generation and randomly distributed among lines. This overall stability of the mean for a given population allows us to conclude that the greater differences, which were sometimes observed between geographic populations, have a genetic basis.

For the three populations investigated here, it was not possible to study the isofemale lines in their first generation of laboratory. Such isofemale lines are submitted to genetic drift but drift, alone, should increase the between line variance without changing their overall mean. On the other hand, laboratory cultures are submitted to new conditions very different from those prevailing in nature: some directional selection for a better laboratory adaptation is expected. However, such adaptation should be the same for the various populations and, in the long term, converge to a similar phenotype. Thus, the consistent differences observed here between the geographic populations reflect physiological properties existing in nature. These differences need to be discussed according to the ecological and climatic conditions existing in the countries of origin.

As stated previously, temperate populations are submitted to different environmental selective pressures in their successive generations (David et al, 1984). In the French locality from which flies were collected, the average annual temperature is about $15^{\circ} \mathrm{C}$ and, because of seasonal variations, the development of generations is possible only in Spring, Summer and Autumn. A major challenge for the flies is overwintering while the desiccation stresses are limited. In Tunisia, the average annual temperature is higher $\left(21^{\circ} \mathrm{C}\right)$ and development may occur during the Winter months. The major problem is the occurrence of stressful conditions in Summer, during which high temperature is accompanied by a low humidity. Such a heatdesiccation stress occurs in all Mediterranean climates, as is the case, for example, in southern Australia (Davidson, 1989). Finally, in the equatorial environment of the Congo, the average temperature is still higher $\left(25^{\circ} \mathrm{C}\right)$ but remains stable all year round. Seasonal variations are mainly due to rainfall and they affect much more the availability of resources than the relative humidity (Vouidibio, 1985).

For desiccation tolerance, our observations confirm the ecological expectation: the most tolerant flies are found in Tunisia, where a hot, dry Summer, imposes a strong directional selection each year. We thus confirm the observations made in Australian populations (Stanley and Parsons, 1981; Davidson, 1989). Interestingly, Congolian and French populations, in spite of their completely different environments, exhibit very similar properties.

For starvation tolerance, which is probably related to the availability of resources, our results are quite unexpected, since we find that tropical flies are about twice as tolerant as temperate ones. At first, it might be expected that, in the tropics, resources are available all year round and adult flies should find food easily. On the other hand, starvation should be a greater stress in temperate countries, where 
natural populations encounter a scarcity of resources during Winter and Spring in France and during Summer in Tunisia.

Assuming that differences between geographic populations are the consequence of some local adaptations, we need other interpretations. One might be to consider the relationship between starvation survival and temperature (Da Lage et al, 1989). All our experiments were made at $17^{\circ} \mathrm{C}$, a temperature often encountered in France and Tunisia during the breeding season, but not in the Congo. Obviously it is the absolute survival duration, not a relative value, which is selected for in nature. From previous physiological experiments (Da Lage et al, 1989) we know that survival duration in the absence of food is approximately divided by two when the temperature changes from 17 to $25^{\circ} \mathrm{C}$. Thus, the survival of the Congolian flies at $25^{\circ} \mathrm{C}$ would be about $65 \mathrm{~h}$, ie very similar to that of French flies at $17^{\circ} \mathrm{C}$. This interpretation is, however, not valid for the Tunisian population, since ecological observations suggest that a scarcity of resources occurs during the hottest months of the year, during which temperatures exceed $25^{\circ} \mathrm{C}$. In this case, we may argue that, during the Mediterranean Summer, flies are more likely to die from desiccation than from starvation, so that the capacity to withstand starvation is an adaptive phenotype only during the colder months.

These observations show that more numerous populations living under a diversity of climates should be investigated if we are to correlate environmental and physiological variables. These relationships could be much more complex than expected with simple natural selection models in which each environmental factor is considered independently of the other.

\section{ACKNOWLEDGMENTS}

We thank J Vouidibio, Y Carton and B Delay for providing the populations from Congo, Tunisia and France, and SF McEvey for help with the manuscript.

\section{REFERENCES}

Arlian L, Eckstand I (1975) Water balance in Drosophila pseudoobscura and its ecological implications. Ann Entomol Soc Am 68, 827-832

Capy P, Pla E, David JR (1990) Variability of morphometrical traits within and between natural populations of Drosophila melanogaster and $D$ simulans (submitted)

Carton Y, Capy P, Nappi AJ (1989) Genetic variability of host-parasite relationship traits: utilization of isofemale lines in a Drosophila simulans parasitic wasp. Genet Sel Evol 21, 437-446

Da Lage JL, Capy P, David JR (1989) Starvation and desiccation tolerance in Drosophila melanogaster adults: effects of environmental temperature. J Insect Physiol 35, 453-457

David JR (1979) Utilization of morphological traits of the analysis of genetic variability in wild populations. Aquilo Ser Zool 20, 49-61

David JR, Capy P (1988) Genetic variation of Drosophila melanogaster natural populations. Trends Genet 4, 106-111 
David JR, Clavel M-F (1965) Interaction entre le génotype et le milieu d'élevage. Conséquences sur les caractéristiques du développement de la Drosophile. Bull Biol Fr Belg 99, 369-378

David JR, Tsacas L (1981) Cosmopolitan, subcosmopolitan and widespread species: different strategies in the Drosophilid family. CR Soc Biogéogr 57, 11-26

David J, Cohet Y, Fouillet P (1975) Physiologie de l'inanition et utilisation des réserves chez les adultes de Drosophila melanogaster. Archs Zool Exp Gen 116, 4, 579-590

David J, Allemand R, Van Herrewege J, Cohet Y (1983) Ecophysiology: abiotic factors. In: Genetics and Biology of Drosophila (Ashburner M, Carson HL, Thompson JN, eds) Academic Press, London, Vol 3, 105-170

David JR, Louis J, McKenzie JA, Rocha-Pite MT, Vouidibio J (1984) Comparative demography of the cosmopolitan sibling species, Drosophila melanogaster and $D$ simulans under tropical and temperate climate. Annls Soc Entomol Fr 20, 135-142 Davidson JK (1988) Extreme of climate and genetic heterogeneity in Australian populations of the dipteran species Drosophila melanogaster. J Biogeogr 15, 481487

Davidson JK (1989) Non-parallel geographic patterns for tolerance to cold and desiccation in Drosophila melanogaster and D simulans Aust $J$ Zool (in press)

Fairbanks LD, Burch GE (1970) Rate of water loss and water and fat content of adults of Drosophila melanogaster of different ages. J Insect Physiol 16, 1429-1436 Falconer DS (1981) Introduction to quantitative genetics. Longman, London

Hoffmann AA, Parsons PA (1988) The analysis of quantitative variation in natural populations with isofemale strains. Genet Sel Evol 20, 87-98

Hoffmann AA, Parsons PA (1989a) Selection for increased desiccation resistance in Drosophila melanogaster: additive genetic control and correlated responses for other stress. Genetics 122, 837-845

Hoffmann AA, Parsons PA (1989b) An integrated approach to environmental stress tolerance and life-history variation: desiccation tolerance in Drosophila. Biol J Linn Soc 37 (in press)

Parsons PA (1980) Parallel climatic races for tolerances to high temperaturedesiccation stress in two Drosophila species. J Biogeogr 7, 97-101

Parsons PA (1983) The Evolutionary Biology of Colonizing Species. Cambridge University Press, Cambridge

Parsons PA (1987) Evolutionary rates under environmental stress. Evol Biol 21, 311-357

Service PM (1987) Physiological mechanisms of increased stress resistance in Drosophila melanogaster selected for postponed senescence. Physiol Zool 60, 321326

Service PM, Hutchinson EW, Mackinley MD, Rose MR (1985) Resistance to environmental stress in Drosophila melanogaster selected for postponed senescence. Physiol Zool 58, 380-389

Slatkin M (1981) Populational heritability. Evolution 35, 859-871

Stanley SM, Parson PA (1981) The response of the cosmopolitan species, Drosophila melanogaster, to ecological gradients. Proc Ecol Soc Aust 11, 121-130

Vouidibio J (1985) Ecologie des populations et biologie évolutive des drosophiles en Afrique équatoriale (Congo). Thèse doc état, Univ Paris 12 